\title{
BMJ Open Association between hospitalisation for ambulatory care-sensitive conditions and primary health care physician specialisation: a cross-sectional ecological study in Curitiba (Brazil)
}

To cite: Afonso MPD, Shimizu HE, MerchanHamann $\mathrm{E}$, et al. Association between hospitalisation for ambulatory care-sensitive conditions and primary health care physician specialisation: a cross-sectional ecological study in Curitiba (Brazil). BMJ Open 2017;7:e015322. doi:10.1136/ bmjopen-2016-015322

- Prepublication history for this paper is available online. To view these files please visit the journal online (http://dx.doi org/10.1136/bmjopen-2016015322).

Received 26 November 2016 Revised 29 May 2017 Accepted 14 June 2017

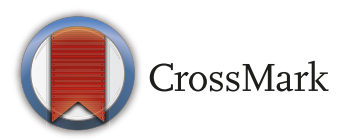

'Departamento de Saúde Coletiva, Faculdade de Ciências da Saúde, Universidade de Brasília, Brasília, Brazil

${ }^{2}$ Programa de Mestrado Profissional, Fundação Pedro Leopoldo, Pedro Leopoldo, Brazil

Correspondence to Dr Marcelo P D Afonso; pellizzaro@gmail.com

\section{ABSTRACT}

Introduction Hospitalisation for ambulatory care-sensitive conditions (HACSCs) is frequently used as an indicator of the quality and effectiveness of primary healthcare (PHC) services around the world. The aim of the present study was to evaluate whether the PHC model (family health strategy (FHS) $x$ conventional) and the availability of specialised PHC physicians is associated or not with total hospitalisation or HACSCs in the National Health System (SUS) of the municipality of Curitiba, Paraná state (PR), Brazil.

Methodology This is a cross-sectional ecological study using multiple linear regression with socioeconomic and professional data from municipal health units (MHUs) between 1 April 2014 and 31 March 2015.

Results After adjustment for age and sex and control of socioeconomic variables, the FHS model was associated with six fewer HACSCs a year per 10000 inhabitants in relation to the conventional model and the availability of one family physician at each FHS model MHU per 10000 inhabitants was associated with 1.1 fewer HACSCs for heart failure a year per 10000 inhabitants. Basic specialists (clinicians, paediatricians and obstetrician/ gynaecologists) and subspecialists showed no significant association with HACSC rates.

Conclusion These results obtained in a major Brazilian city reinforce the role of FHS as a priority $\mathrm{PHC}$ model in the country and indicate the potentially significant impact of specialising in family medicine on improving the health conditions of the population.

\section{INTRODUCTION}

Primary healthcare (PHC) is the first-contact level and the backbone of rational National Health Systems, responsible for providing accessible, continuous, comprehensive and coordinated healthcare to the population. ${ }^{1}$ An important indicator of the quality and effectiveness of this care is the rate of hospitalisations for ambulatory care-sensitive conditions (HACSCs)..$^{2-5}$ These are conditions of needed hospitalisation that can be avoided

\section{Strengths and limitations of this study}

- This study was carried out in an important Brazilian city with high primary healthcare $(\mathrm{PHC})$ service coverage where resources are uniformly distributed among health units regardless of their PHC model, allowing reliable analysis of the association between PHC model, medical specialisation and hospitalisations for ambulatory care-sensitive conditions.

- The socioeconomic and hospitalisation data used were obtained from reliable official sources.

- Hospitalisations were adjusted for age, sex and socioeconomic variables, important confounders for the outcomes of interest.

- The short duration of PHC physicians' presence in the municipal health units (MHUs) assessed (12 months) and the small number of MHUs studied reduced the power of the study.

- The cross-sectional ecological design is unable to establish a causality relationship between the variables studied.

through the provision of timely and qualified PHC services by (1) preventing the onset of disease, (2) adequately controlling acute illness or (3) effectively managing chronic conditions. ${ }^{6}$ Brazil has had a National List of Ambulatory Care-Sensitive Conditions since $2008 .^{78}$

In Brazil, the preferred PHC organisation model within the National Health System (SUS) is the family health strategy (FHS). ${ }^{9}$ FHS teams consist of a general practitioner, a professional nurse, 1 or 2 assistant nurses and 4-12 community health agents, caring for 3000 people on average. ${ }^{9}$ Nevertheless, the so-called conventional model based on ambulatory care in the basic specialties of paediatrics, internal medicine, gynaecology and obstetrics persists, particularly in large 
cities. ${ }^{10}{ }^{11}$ PHC physicians are not legally required to have a specialty. Physicians become specialists in family medicine in Brazil after completing 2-year medical residency programme or through a certification examination after 4 years' experience in the field.

Several studies have demonstrated an association between FHS coverage and a decline in HACSCs. ${ }^{12-15}$ Between 1999 and 2007, chronic HACSC rates in municipalities with greater FHS coverage were $13 \%$ lower in relation to those with less coverage, reaching $23 \%$ for hospitalisation due to asthma. ${ }^{16}$

A recent study found a significant association between specialising in Family Medicine (FM) and the strength of PHC attributes in the FHS of an important Brazilian capital, measured using the PCA tool. ${ }^{17}$ Thus, it can be speculated that specific medical training for PHC in Brazil is related to both major and intermediate health outcomes. If lower HACSC rates are expected with access to qualified clinical care, medical specialties aimed at training PHC professionals should, in theory, influence this outcome. However, studies that assess the relationship between the specialties of PHC physicians and health outcomes remain scarce.

The aim of the present study was to evaluate whether the PHC model and the availability of specialised PHC physicians are associated or not with total hospitalisation or HACSC rates in the National Health System (SUS) of the municipality of Curitiba, Paraná state (PR), Brazil.

\section{METHODOLOGY}

This is a cross-sectional ecological study conducted in the municipality of Curitiba (PR), Brazil. The municipality exhibits high PHC coverage, particularly in terms of FHS, which reached $52 \%$ of the population in April 2014. ${ }^{18}$ Moreover, a high number of family physicians is reported in comparison to other Brazilian capitals, and healthcare services have been computerised for over a decade. ${ }^{10}$ The units of analysis were municipal health units (MHUs), classified as a family health strategy (FHS) or conventional (EAB) in accordance with the PHC model of their teams.

\section{Data}

Socioeconomic data by census tract were obtained from 2010 Census databases, provided by the Brazilian Institute of Geography and Statistics.

Information on hospital admissions was obtained from the Hospital Information System (SIH), through registered Hospitalisation Authorisation Forms (AIH). Inclusion criteria were single or initial AIH, valid until June 2015, for Curitiba (PR) residents hospitalised in the municipality between 1 April 2014 and 31 March 2015. Hospital admissions for childbirth (International Classification of Diseases, 10th edition (ICD-10) O80 to O84) were excluded as physiological events. ${ }^{7}$

AIH information and socioeconomic data were aggregated at the level of the MHU coverage areas, using
QuantumGIS software (QGIS), V.2.10 Pisa. Addresses on AIH were geocoded using the Michael Minn QGIS plugin (MMQGIS) and GoogleMaps server.

Quantitative data and information on the specialties of PHC physicians in Curitiba (PR) during the study period were obtained from databases of the Curitiba Municipal Health Department (SMS-Curitiba), Regional Board of Medicine for the State of Paraná, Brazilian Medical Association (AMB) and the National Medical Residency Committee (CNRM).

The MHU model and doctors' working hours were used as predictor variables. Doctors were classified as (1) family physicians (FP); (2) basic specialty physicians (BSP) or (3) subspecialty physicians (SUBP) if they had concluded their medical residency through the CNRM or been awarded a degree by a scientific association recognised by the AMB prior to 31 May 2015, in the fields of (1) family medicine (FM); (2) internal medicine, paediatrics, gynaecology and obstetrics and (3) other medical specialties, respectively.

The average supply of doctors was calculated using the mean total working hours of physicians in each MHU during the study period. For physicians who remained at the same MHU for the 12-month study period, total effective working hours were added to working hours per category for each MHU, according to the classification above. For each amount, the ratio of working hours to the total population residing in the MHU coverage area (2010 Census) was calculated. In order to facilitate understanding, variables were presented as 'full-time equivalents', which represent the number of physicians with a 40-hour work week.

As outcome variables for each MHU, total hospitalisation rates were calculated, as well as HACSCs and the main ambulatory care-sensitive condition per age group, namely bacterial pneumonia (BP) in childhood (0-14 years), angina in adulthood (15-64 years) and heart failure (HF) in the elderly ( $\geq 65$ years). Hospitalisation rates were standardised for age and sex via the direct method, using the structure of the population of Curitiba (PR) according to the 2010 Census as reference. In order to calculate hospitalisation rates, the population in the respective MHU coverage areas was used as a denominator, in accordance with the 2010 Census. HACSCs were defined as those for which the 'main diagnosis' field of the AIH contained a disease classified by an ICD-10 code as belonging to the Brazilian List of Ambulatory Care-Sensitive Conditions. ${ }^{8}$ Due to its high incidence rate, records for which the main diagnosis was ICD-10 J18.9 (pneumonia; unspecified organism) were included in this study as BP.

Four socioeconomic variables relevant to the studied outcomes were adopted as context per MHU: (1) literacy rate in the population aged $\geq 10$ years (Lit. Rt); (2) percentage of blacks, mulattos and native Brazilians (Pop. Perc); (3) per capita income (Income) and (4) percentage of households with a per capita income below half the minimum wage (Perc. House). 


\section{Data analysis}

SPSS Statistics software V.18 (PASW Statistics 18) was used for data analysis. Calculation of the variance inflation factor (VIF) identified high collinearity (VIF $>5$ ) between the socioeconomic variables Lit.Rt, Pop. Perc. and Perc. House, preventing their concomitant use in the analysis, but not between variables related to physician working hours. Working hours per medical category were similar between EAB and FHS model MHUs, except for FP, whose working hours were 15 times higher at FHS model MHUs than conventional (EAB) units.

In order to estimate the effects of predictor variables independently of socioeconomic variables, hierarchical linear regression with stepwise-backward elimination was carried out for each dependent variable studied, with an F-to-enter statistic of 0.10 and F-to-remove of 0.20 , initially for all the MHUs and subsequently for FHS model MHUs. The variable related to the FP category was only used in the latter given its significant association with this model.

Two models were constructed. Model 1 included the variable 'income' and, among the socioeconomic variables exhibiting high collinearity, the variable with the greatest beta value in simple regression for the dependent variable under study. Variables with a $p$ value $<0.20$ were maintained and fixed for model 2, which included the other variables under study. The results were presented as non-standardised coefficients and considered significant at $5 \%$. Results significant at $10 \%$ were also identified.

\section{RESULTS}

The study included 109 MHUs, 44 (40.4\%) of which were conventional (EAB) and $65(59.6 \%)$ applied the FHS model. Of the FHS model MHUs, one $(0.9 \%)$ was created during the study period. In April 2015, SMS-Curitiba had 512 PHC physicians, 433 of which remained at the same MHU throughout the 12-month study period. Seventy-seven (17.8\%) were classified as FP; $117(27.0 \%)$ as BSP; $37(8.5 \%)$ as SUBP and 202 (46.7\%) had no specialty recognised by the CNRM or AMB.

Figure 1 shows the selection of AIH for analysis according to inclusion and exclusion criteria. The mean values of each variable studied are shown in table 1 , accompanied by SD.

The coverage areas of FHS model MHUs exhibited worse socioeconomic conditions compared with EAB units. Among FHS model MHUs, a negative association was observed between equivalent FP and the variables Lit. Rt and income. The same was true for the variables total equivalent and SUBP equivalent, whereas the opposite was observed for the group BSP equivalent.

The results of hierarchical linear regression coefficients in models 1 and 2 are presented in tables 2 and 3 , respectively. Values statistically significant at $5 \%$ are identified in the tables. Results statistically significant at $10 \%$ are also marked in table 3 .

Socioeconomic variables were alternately significant for all the dependent variables when all the MHUs were analysed, except for angina-related HACSCs, indicating that the better the socioeconomic conditions, the lower the hospitalisation rates. In analysis of FHS model MHUs, only the association between the Lit.Rt and hospitalisation rates for $\mathrm{BP}$ was statistically significant at $5 \%$.

The FHS model was associated with fewer HACSCs (on average 6.0 fewer hospitalisations a year per 10000 inhabitants in relation to the EAB model), statistically significant at $5 \%$. A statistically significant association was also observed between the availability of FP and fewer HACSCs for HF in FHS model MHUs (1.1 fewer hospitalisations a year per 10000 inhabitants for every 40-hour week FP per 10000 inhabitants). The variable total equivalent was significantly correlated with higher HACSC rates in all the MHUs, as well as higher total hospitalisation rates and admissions due to ambulatory care-sensitive conditions in FHS model MHUs. The variables average supply equivalent, BSP equivalent and SUBP equivalent were not significantly associated with any of the outcomes studied.

Some results were only statistically significant at $10 \%$, as follows: (1) FHS model and lower HACSC rates for HF and BP; (2) FP equivalent and lower total hospitalisation and HACSC rates in FHS model MHUs; (3) BSP equivalent and lower total hospitalisation rate in FHS model MHUs; (4) total equivalent and higher total hospitalisation rate in total MHUs and higher HACSC rates for $\mathrm{HF}$ under the FHS model and (5) Lit.Rt and lower HACSC rates under the FHS model.

\section{DISCUSSION}

In the present study, after adjustment for age and sex and control of socioeconomic variables, lower HACSC rates were significantly associated with the FHS model and the presence of FP in the municipality of Curitiba (PR), Brazil. No significant associations were observed between HACSCs and other medical specialties, while worse results were found for the total number of doctors present over the 12 month study.

The association between the FHS model and low HACSC rates is consistent with other studies. ${ }^{12} 1315$ Although Curitiba exhibited one of the lowest HACSC rates among Brazilian capitals, the difference between the models (FHS and EAB) was equivalent to $13 \%$ of the municipality's HACSCs for the period. The FHS model was also correlated with fewer hospitalisations for $\mathrm{HF}$ and $\mathrm{BP}$, both statistically significant at $10 \%$. These results reinforce the knowledge accumulated in the literature, which justify maintaining, expanding and consolidating this strategy in the country, even in socially and economically developed municipalities such as Curitiba.

Among the FHS model units, the presence of FP was significantly associated with lower hospitalisation rates for HF, the main cause of HACSCs in the elderly population of Curitiba during the study period. The presence of one 40-hour work week FP per 10000 inhabitants was related to $14 \%$ fewer hospitalisations for this condition in the municipality. This suggests that the presence of these 


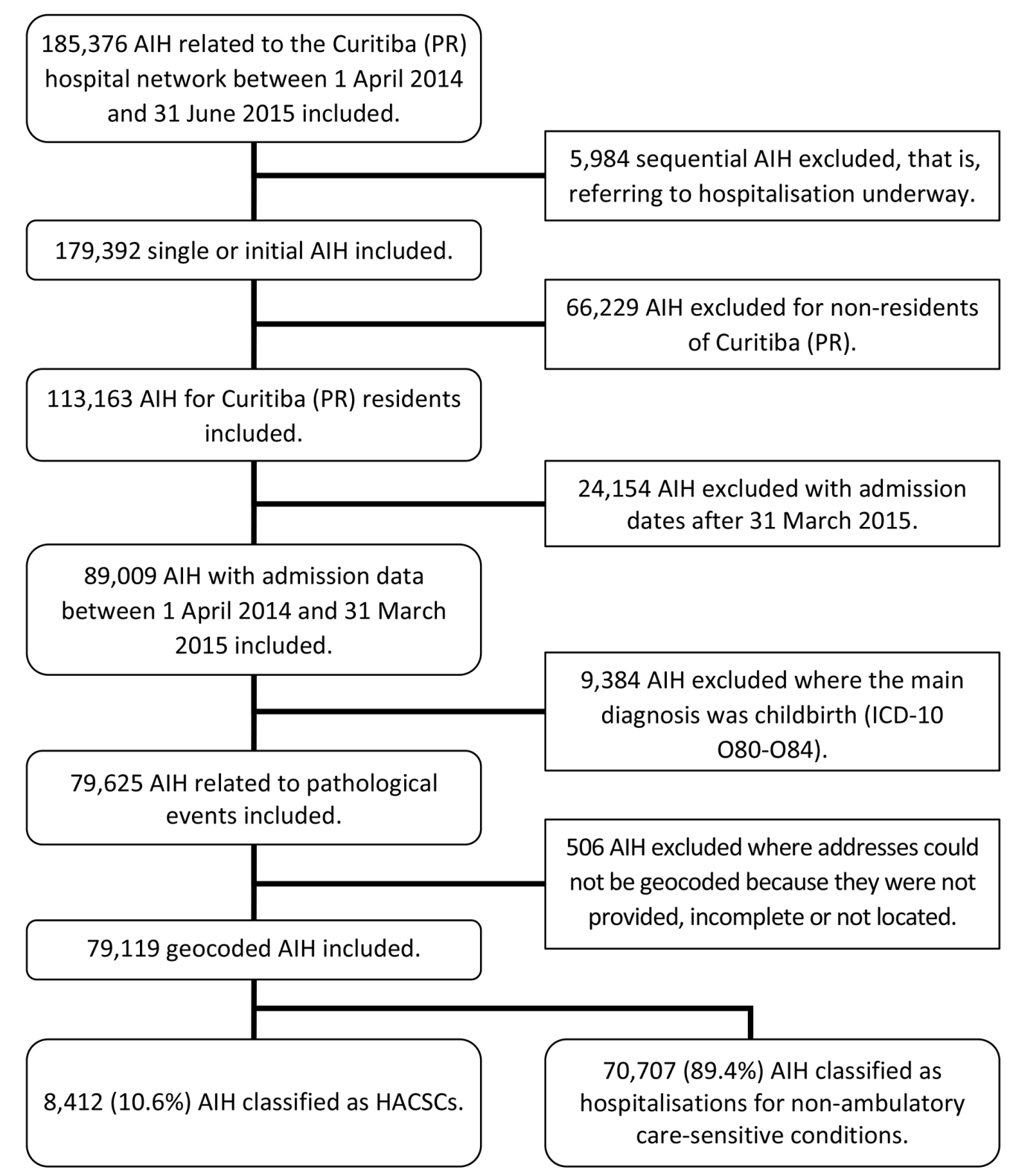

Figure 1 Selection of $\mathrm{AlH}$ for analysis according to inclusion and exclusion criteria. AlH, hospitalisation authorisation form; HACSCs, hospitalisation for ambulatory care-sensitive conditions.

professionals could have a potentially significant impact on the country, as HF is also the main cause of HACSCs in Brazil. ${ }^{19}$

FP were also significantly associated with the total hospitalisation and overall HACSC rates. Although results were significant at $10 \%$ but not $5 \%$, the association was clinically significant. For every 40-hour work week physician per 10000 inhabitants, there were 3.2 fewer HACSCs a year per 10000 inhabitants. Considering the recommendation of the 2012 National Primary Care Policy that each FHS team should cover an average of 3000 people, based on the results found, one would expect a reduction of 9.6 HACSCs a year per 10000 inhabitants, if three FP are present in comparison to three physicians without this specialty. ${ }^{9}$ This could represent a $>20 \%$ drop in the average for the municipality, regardless of other factors.
Despite being associated with the PHC model at $10 \%$ significance, hospitalisation for $\mathrm{BP}$, the main cause of HACSCs among children (0-14 years), did not appear to be related to the presence of FP in this study. This can be explained by the fact that BP is an acute condition, unlike HF. Considering the essential attributes of PHC, the literature indicates a strong overall relationship between access and HACSCs. ${ }^{20-22}$ In terms of longitudinal care/continuity, studies have found an inverse association with only chronic ambulatory care-sensitive conditions. ${ }^{23}{ }^{24}$ Thus, it can be concluded that the access provided by MHUs is more relevant when treating $\mathrm{BP}$, which is less influenced by FM specialty. On the other hand, in cases of HF, both access and qualified longitudinal care are essential to achieve fewer hospitalisations. 
Table 1 Means and SD for socioeconomic variables, hospitalisation rates and full-time equivalents according to MHU models, Curitiba (PR), Brazil

\begin{tabular}{|c|c|c|c|c|c|c|}
\hline \multirow[b]{2}{*}{ Study variables } & \multicolumn{2}{|c|}{ EAB ( $n=44$ MHUs) } & \multicolumn{2}{|c|}{ FHS (n=65 MHUs) } & \multicolumn{2}{|c|}{ Total (n=109 MHUs) } \\
\hline & Mean & SD & Mean & SD & Mean & SD \\
\hline \multicolumn{7}{|l|}{ Socioeconomic variables } \\
\hline Lit. Rt (\%) & 98.4 & 0.7 & 96.8 & 1.4 & 97.4 & 1.4 \\
\hline Pop. Perc. (\%) & 16.8 & 5.4 & 27.6 & 8.2 & 23.2 & 8.9 \\
\hline Income (R\$) & 1232.57 & 493.16 & 777.17 & 429.07 & 961.00 & 506.28 \\
\hline Perc.House (\%) & 6.0 & 2.6 & 12.6 & 5.8 & 10.0 & 5.8 \\
\hline \multicolumn{7}{|l|}{ Hospitalisation rates per year per 10000 inhabitants } \\
\hline Total & 418.7 & 127.9 & 499.4 & 154.0 & 466.8 & 148.9 \\
\hline HACSCs & 46.0 & 13.7 & 47.7 & 14.2 & 47.0 & 14.0 \\
\hline $\mathrm{BP}$ & 11.8 & 5.9 & 12.9 & 6.2 & 12.5 & 6.1 \\
\hline Angina & 8.2 & 3.2 & 8.3 & 4.2 & 8.3 & 3.9 \\
\hline HF & 8.0 & 2.9 & 7.7 & 3.2 & 7.8 & 3.1 \\
\hline \multicolumn{7}{|l|}{ Full-time equivalents per 10000 inhabitants } \\
\hline Average supply & 2.10 & 0.76 & 3.51 & 1.50 & 2.94 & 1.43 \\
\hline FP & 0.06 & 0.12 & 0.89 & 1.10 & 0.55 & 0.95 \\
\hline BSP & 0.75 & 0.47 & 0.21 & 0.40 & 0.43 & 0.50 \\
\hline SUBP & 0.17 & 0.20 & 0.19 & 0.50 & 0.18 & 0.40 \\
\hline Physicians at the same MHU for 12 months - total & 1.77 & 0.73 & 2.58 & 1.28 & 2.25 & 1.16 \\
\hline
\end{tabular}

BP, bacterial pneumonia; BSP, basic specialty physicians (clinicians, paediatrics and gynaecologists); EAB, conventional health unit; FHS, family health strategy; FP, family physician; HACSCs, hospitalisation for ambulatory care-sensitive conditions; HF, heart failure; Income, per capita income; Lit. Rt, literacy rate in the population aged $\geq 10$ years; MHU, municipal health unit; Perc. House, percentage of households with a per capita income below minimum wage; Pop. Perc., percentage of blacks, mulattos and native Brazilians; SUBP, subspecialty physicians.

Hospitalisations for angina, the main cause of HACSC in the 15-64 year age group, were not associated with any variables, whether socioeconomic or health service-related. The short study period of 12 months may explain this finding. Moreover, this condition typically develops over decades and is heavily influenced by risk factors related to the individual's lifestyle. Although angina is considered an ambulatory care-sensitive condition, the extent to which healthcare services can modify its progression is debatable.

Table 2 Results of hospitalisation coefficients and $\mathrm{p}$ values for model 1 of the socioeconomic variable for all MHUs and FHS model MHUs, Curitiba (PR), Brazil

\begin{tabular}{|c|c|c|c|c|c|c|c|c|c|c|}
\hline \multirow[b]{2}{*}{ Socioeconomic variables } & \multicolumn{2}{|l|}{ Total } & \multicolumn{2}{|c|}{ HACSCs } & \multicolumn{2}{|l|}{ HF } & \multicolumn{2}{|l|}{ Angina } & \multicolumn{2}{|l|}{ BP } \\
\hline & Coeff. & p Value & Coeff. & p Value & Coeff. & p Value & Coeff. & p Value & Coeff. & p Value \\
\hline \multicolumn{11}{|l|}{ Total (n=109 MHUs) } \\
\hline Lit.Rt (\%) & $-55.0^{*}$ & $<0.001$ & . & . & -0.1 & 0.861 & -0.1 & 0.801 & $-1.7^{\star}$ & $<0.001$ \\
\hline Income (R\$ 100.00) & $-5.2 \dagger$ & 0.129 & $-1.2^{\star}$ & $<0.001$ & $-0.2^{\star}$ & 0.007 & -0.1 & 0.347 & -0.1 & 0.382 \\
\hline Perc.House (\%) & . & . & . & . & . & . & . & . & . & . \\
\hline Pop. Perc. (\%) & . & . & 0.2 & 0.504 & . & . & . & . & . & . \\
\hline \multicolumn{11}{|l|}{ FHS model MHUs $(n=64)$} \\
\hline Lit.Rt (\%) & $-42.5^{*}$ & 0.001 & $-3.4^{\star}$ & 0.006 & $-0.5 \dagger$ & 0.059 & . & . & $-1.7^{\star}$ & 0.002 \\
\hline Income (R\$100.00) & 2.2 & 0.688 & -0.4 & 0.440 & -0.1 & 0.784 & -0.1 & 0.804 & 0.1 & 0.535 \\
\hline Perc. House (\%) & . & . & . & . & . & . & -0.1 & 0.480 & . & . \\
\hline Pop. Perc. (\%) & . & . & . & . & . & . & . & . & . & . \\
\hline
\end{tabular}

* (bold) Value $p<0.05$

$\dagger$ (italic) Value $p<0.20$.

BP, bacterial pneumonia; FHS, family health strategy; HACSCs, hospitalisation for ambulatory care-sensitive conditions; HF, heart failure; Income, per capita income; Lit. Rt, literacy rate in the population aged $\geq 10$ years; MHU, municipal health unit; Perc. House, percentage of households with a per capita income below minimum wage; Pop. Perc., percentage of blacks, mulattos and native Brazilians. 


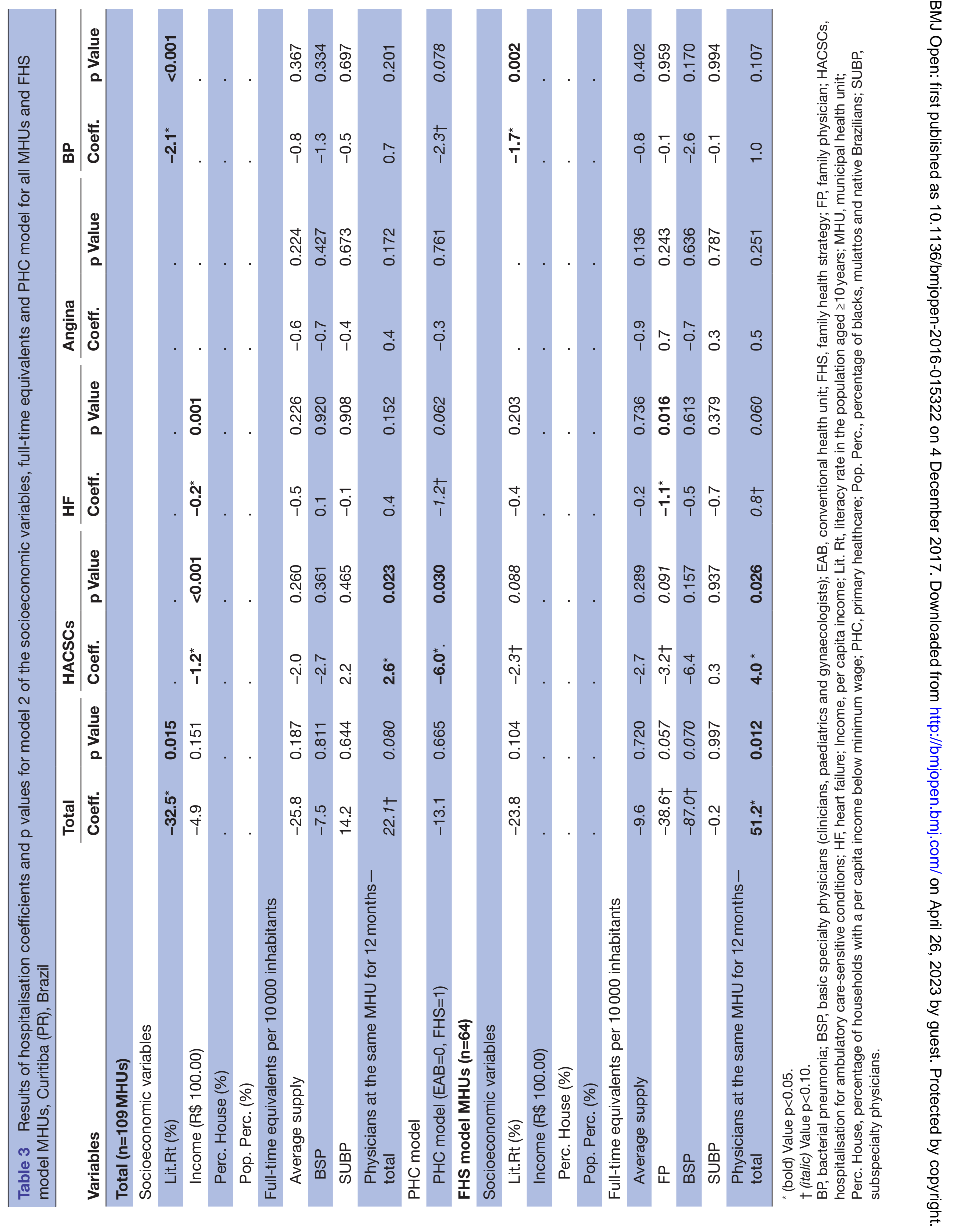


Basic specialists at the same MHU for the 12-month study period were associated to lower total hospitalisation rate in FHS model MHUs at $10 \%$ significance, but not to lower HACSC rates, which suggests it is a spurious association. Subspecialists at the same MHU for the 12-month study period were not significantly related to any of the dependent variables. This finding suggests that FM is superior to other specialties in PHC settings in terms of reducing HACSCs. Contrary to the findings of other studies, the average supply of doctors in the study period was not associated with any of the dependent variables assessed. ${ }^{202}$ This may be due to the adequate supply of physicians in terms of the municipality's needs. Unexpectedly, the total number of doctors at the same MHU throughout the 12-month study, almost half of whom were not registered as specialists on official databases, was significantly related to worse hospitalisation rates for some conditions. Although certain limitations of this study may explain some of these findings, the results strongly suggest that medical specialties in PHC may play an important role in care quality and the impact of outcomes on health, whether positive or negative.

This study includes data from all public admissions to hospitals in Curitiba and all municipal health units, thereby covering the entire public healthcare system. As such, it reliably represents the specific scenario of Curitiba. It is conceivable that other large Brazilian cities with structured PHC coverage, such as Florianopolis and Belo Horizonte, would obtain similar results. Nevertheless, the associations found in this study should be confirmed by further research in these cities, in addition to testing whether they are also present in other scenarios, such as low PHC coverage.

\section{Limitations}

With respect to the limitations, the first is inherent to the study design; as such, it cannot be concluded that the findings presented here on an ecological level necessarily reflect associations on an individual level. However, the hypothesis that both the PHC model and the medical specialty best suited to primary care can reduce HACSCs, one of the main indicators used to assess the quality of PHC, seems plausible.

The study period was too short to properly analyse the outcomes. A study of elderly individuals in the USA suggested a minimum doctor-patient relationship of 5-10 years was needed to obtain a significant variation in the hospitalisation rates of these patients. ${ }^{25}$ However, the high turnover rate of PHC physicians in Brazil combined with the difficulty in collecting older data on municipal health services made it impossible to lengthen the study period.

The small number of MHUs studied (109 MHUs in total and 65 FHS model MHUs) compromised the statistical power and may explain the scarcity of statistically significant results at 5\% significance. As such, we also applied a $10 \%$ significance level for associations initially non-significant at $5 \%$ so as not to neglect clinically meaningful results
Some confounding factors potentially relevant to the outcomes studied were not explored here. These include characteristics of the multidisciplinary team, involvement with teaching activities, when professionals and teams began working in the area, presence of other social resources in the area and the existence of geographic or socio-organisational barriers to access.

Finally, there are two other noteworthy limitations. The study used population data from the 2010 Census, whereas hospitalisation data were from April 2014 to March 2015. In addition, hospitalisation data were obtained from $\mathrm{AIH}$, a hospital reimbursement tool used exclusively in the public health system with no information on private admissions (funded by healthcare plans, health insurance or individuals). However, Curitiba has shown little population change, with growth estimated at only $7 \%$ between 2010 and 2015. This growth is not homogeneous across the municipality and areas with unfavourable socioeconomic conditions show the greatest expansion. ${ }^{26}{ }^{27}$ As such, hospitalisation rates for the most vulnerable regions of Curitiba may have been overestimated in relation to other areas in this study, owing to underestimation of its population in 2015, whose growth potential would have been greater between 2010 and 2015, and non-notification of private hospital admissions in wealthier areas. This did not prevent findings of better outcomes associated with the FHS model and the FM specialty, but may explain the absence and/or fragility of other associations observed as well as the worse outcomes related to the total number of doctors at the same MHU for 12 months.

\section{CONCLUSION}

Based on hospitalisation rates adjusted for age and sex and controlled analysis of socioeconomic factors whose influence on hospitalisation is recognised in the literature, the FHS model was significantly associated with lower HACSC rates and the availability of FP was significantly correlated with lower HACSC rates due to HF in Curitiba (PR), Brazil, from April 2014 to March 2015.

The fact that the best outcomes recorded in a major Brazilian municipality known for its well-organised health system were associated with the FHS model reinforces FHS as the preferred organisation model for PHC in Brazil. On the other hand, the statistically significant association between the presence of FP and lower HF rates, the leading cause of HACSCs among the elderly in Curitiba, may be an effective means of reducing financial costs and human suffering, as the ageing of the Brazilian population suggest a current and future increase in chronic disease.

It is important to underscore that basic specialties, as well as those in other medical fields (called subspecialties) were not significantly associated with any HACSC rates studied. Finally, the association between the total number of doctors at the same MHU for the 12-month study period, almost half of whom were not specialists, and higher hospitalisation rates calls for urgent reflection on the possibility of iatrogenesis in PHC and the need 
to implement mandatory medical specialties after the completion of undergraduate medical courses, as occurs in several first world countries. The findings of this study should be confirmed by further in-depth assessments that eliminate or minimise the limitations presented.

Acknowledgements MPDA gratefully acknowledge $\mathrm{Dr}$ Juliana Oliveira Soares and $\mathrm{Dr}$ Juan Gérvas for the final revision of the manuscript, and the assistance of $\mathrm{Dr}$ Bruno Musso in earlier stages of this research. The authors are also grateful to the staff of the Municipal Health Department of Curitiba/PR (SMS-Curitiba), especially Dr Luiz Ricardo Stinghen and Dr Paulo Poli, for providing a significant portion of the data used here.

Contributors MPDA: conceived the study; collected and organized data; drafted the manuscript. MPDA, HES, EMH and WMR: designed the study. MPDA, HES, EMH, WMR and TA: analyzed data. All authors: revised the article and agreed with the final version and findings.

Funding The publication fee of this article was partially funded by Universidade de Brasília (Brasília, Brazil). Call for financing grant DPI/DPG-UnB nº 01/2017 (07 August 2017).

Competing interests MPDA served as vice president for the Family Medicine Association of Brasilia (ABrMFC) Board of Directors from 2014 to 2015. ABrMFC is a non-profit professional and scientific regional association affiliated with the Brazilian Family Medicine Society (SBMFC).

Ethics approval This study was approved by the Research Ethics Committees of the Coordinating (FS/UnB, CAAE 42275414.0.0000.0030) and Partner Institutions (SMS-Curitiba, CAAE 42275414.0.3001.0101).

Provenance and peer review Not commissioned; externally peer reviewed.

Data sharing statement The hospitalisation rates, socioeconomic indicators and medical workload per MHU have not been published and are available by emailing MPDA.

Open Access This is an Open Access article distributed in accordance with the Creative Commons Attribution Non Commercial (CC BY-NC 4.0) license, which permits others to distribute, remix, adapt, build upon this work non-commercially, and license their derivative works on different terms, provided the original work is properly cited and the use is non-commercial. See: http://creativecommons.org/ licenses/by-nc/4.0/

(c) Article author(s) (or their employer(s) unless otherwise stated in the text of the article) 2017. All rights reserved. No commercial use is permitted unless otherwise expressly granted.

\section{REFERENCES}

1. Starfield B. Primary Care: Balancing Health Needs, Services, and Technology. Oxford: Oxford University Press, 1998:19-34.

2. Purdy S, Griffin T, Salisbury C, et al. Ambulatory care sensitive conditions: terminology and disease coding need to be more specific to aid policy makers and clinicians. Public Health 2009;123:169-73.

3. Agency for Healthcare Research and Quality. Guide to Prevention Quality Indicators: Hospital Admission for Ambulatory Care Sensitive Conditions. AHRQ Quality Indicators, 2007.

4. OECD. Health at a Glance 2015: OECD Indicators. Paris: OECD Publishing, 2015:

5. Viacava F, Ugá MAD, Porto S, et al. Avaliação de Desempenho de Sistemas de Saúde: um modelo de análise. Cien Saude Colet 2012;1734:921-34.

6. Billings J, Zeitel L, Lukomnik J, et al. Impact of socioeconomic status on hospital use in New York City. Health Aff 1993;12:162-73.

7. Alfradique ME, Bonolo PF, Dourado I, et al. Ambulatory care sensitive hospitalizations: elaboration of Brazilian list as a tool for measuring health system performance (Project ICSAP--Brazil). Cad Saude Publica 2009;25:1337-49.

8. Brasil. Ministério da Saúde. Secretaria de Atenção à Saúde. Portaria $n^{\circ}$ 221, de 17 de abril de 2008. Seção I. Brasil: Diário Oficial da União de 18 de abril de, 2008: pp. 70-6.

9. Brasil. Ministério da Saúde. Política Nacional de Atenção Básica PNAB 2012. Brasília: Ministério da Saúde, 2012: pp. 1-110.

10. Organização Pan-Americana da Saúde. A implantação do modelo de atenção as condições crônicas em Curitiba: resultados do laboratório de inovação sobre atenção às condições crônicas na atenção primária em saúde. Brasília: Organização PanAmericana da Saúde, Conselho Nacional de Secretários de Saúde, 2013:28-46.

11. Giovanella $L$, de Mendonça MHM. et alAtenção Primária à Saúde. In: Giovanella L, Escorel S, Lobato L de VC, de NJC, de CAl, ; eds. Políticas e Sistema de Saúde no Brasil. Rio de Janeiro: Fiocruz, 2008:575-625.

12. Fernandes VBL, Caldeira AP, De FAA, et al. Internações sensíveis na atenção primária como indicador de avaliação da Estratégia Saúde da Família. Rev Saude Publica 2009;43:928-36.

13. Guanais F, Macinko J. Primary care and avoidable hospitalizations: evidence from Brazil. J Ambul Care Manage 2009;32:115-22.

14. Nedel FB, Facchini LA, Martín-Mateo M, et al. Programa Saúde da Família e condições sensíveis à atenção primária, Bagé (RS). Rev Saude Publica 2008;42:1041-52.

15. Dourado I, Oliveira VB, Aquino R, et al. Trends in Primary Health Care-sensitive Conditions in Brazil: The Role of the Family Health Program (Project ICSAP-Brazil). Med Care 2011;49:577-84.

16. Macinko J, Dourado I, Aquino R, et al. Major expansion of primary care in Brazil linked to decline in unnecessary hospitalization. Health Aff 2010;29:2149-60.

17. Lermen Junior N. Análise comparativa da avaliação da Atenção Primária à Saúde prestada por parte de Médicos com e sem especialização em Medicina de Família e Comunidade atuantes na Estratégia de Saúde da Família do município de Florianópolis. Brasil Dissertação de Mestrado: Università di Bologna, 2011:1-49.

18. Curitiba. Prefeitura Municipal. Secretaria Municipal da Saúde. Atenção Primária. 2016. 1-3 http://www.saude.curitiba.pr.gov.br/ index.php/assistencia/atencao-basica (accessed $18 \mathrm{Jul}$ 2016).

19. Rodrigues-Bastos RM, Campos EM, Ribeiro LC, et al. Hospitalizations for ambulatory care-sensitive conditions, Minas Gerais, Southeastern Brazil, 2000 and 2010. Rev Saude Publica 2014;48:958-67.

20. Rosano A, Loha CA, Falvo R, et al. The relationship between avoidable hospitalization and accessibility to primary care: a systematic review. Eur J Public Health 2013;23:356-60.

21. Gibson OR, Segal L, McDermott RA. A systematic review of evidence on the association between hospitalisation for chronic disease related ambulatory care sensitive conditions and primary health care resourcing. BMC Health Serv Res 2013;13:1.

22. van Loenen T, van den Berg MJ, Westert GP, et al. Organizational aspects of primary care related to avoidable hospitalization: a systematic review. Fam Pract 2014;31:502-16 http://fampra. oxfordjournals.org/content/31/5/502.long.

23. Cabana MD, Jee SH. Does continuity of care improve patient outcomes? J Fam Pract 2004;53:974-80.

24. Kearley KE, Freeman GK, Heath A. An exploration of the value of the personal doctor-patient relationship in general practice. $\mathrm{Br} J$ Gen Pract 2001;51:712-8.

25. Weiss LJ, Blustein J. Faithful patients: the effect of long-term physician-patient relationships on the costs and use of health care by older Americans. Am J Public Health 1996;86:1742-7.

26. Curitiba. Prefeitura Municipal. Instituto de Pesquisa e Planejamento Urbano de Curitiba. Análise do Censo 2010 - População. 2012:1-9 http://www.ippuc.org.br/visualizar.php?doc=http://admsite2013. ippuc.org.br/arquivos/documentos/D356/D356_003_BR.pdf (accessed 18 Jul 2016).

27. Brasil. Ministério do Planejamento Orçamento e Gestão. Instituto Brasileiro de Geografia e Estatística. Curitiba. Brasília: IBGE Cidades, 2016:1-2. http://cod.ibge.gov.br/8XS. (accessed 18 Jul 2016). 